\title{
Debatir el populismo: Lógicas, afectos y ciclos de conflictividad. Introducción al Dossier
}

\author{
Jorge Daniel Vasquez* \\ Sebastian Raza**
}

A spectre is haunting the world -populism.

Ghita Ionescu y Ernest Gellner (1969: 1)

Aun cuando se le haya declarado muerto y enterrado, con un estaca en el corazón, y sin que nadie haya llorado su muerte, el populismo regresa, como los muertos en vida de la política latinoamericana.

Alan Knight (1992: 239)

¿Qué sucedería si, al igual que Marx [con el comunismo] procuramos conjurar los fantasmas del populismo y tratamos de pensar en el espíritu epocal que lo constituye?

Luciana Cadahia (2016: 52)

$\mathrm{N}$

o es extraño que se identifique al populismo como un espectro o una forma fantasmal de la política. De hecho, en la literatura sobre el populismo tal adjetivación es incorporada en los esfuerzos por definirlo (Arditi, 2004; Panizza, 2005). Tales definiciones, si bien otorgan al populismo un carácter inatrapable (es decir, no circunscrito dentro de una ideología, o forma singular de gobierno), sí van más allá de definiciones operativas que, con el propósito de hacer del populismo un fenómeno susceptible de comparaciones, lo reducen a la combinación, con ciertas variantes, de tres factores: un líder carismático a lá Weber, el establecimiento de la lógica

* Jorge Daniel Vasquez es candidato a Ph.D. en Sociología por la Universidad de Massachussets-Amherst y es docente de la Pontificia Universidad Católica del Ecuador.

** Sebastian Raza es candidato a Ph.D. en Sociología por la Universidad de Cambridge. 
amigo-enemigo a lá Schmitt, y un ejercicio de gobierno que transgrede los cercos institucionales.

Aunque el nombre sea el mismo, lo que entendemos por populismo cambia con cada (re)emergencia del fenómeno y el término. No solo se trata de que el populismo está sujeto a las iteraciones históricas y el uso de nuevos dispositivos mediáticos, sino que emerge en distintas configuraciones político-económicas en las que mercados y Estados operan a distintas escalas. Más importante aún, las formaciones históricas científico-disciplinares concretas lo describen haciendo uso de sus repertorios conceptuales y arsenales metodológicos. Esta metamorfosis del populismo a nivel conceptual e histórico, sin embargo, no clausura la posibilidad de observar los avatares que lo rodean y afirmar su unidad en la diferencia. Para ello, sin embargo, es necesario trazar distinciones que orienten la observación y que permitan realizar valoraciones relevantes.

El presente número sirve como espacio para la expresión de distintas voces de distintos espacios geográficos y teórico-disciplinares que, a primera vista - y de no ser porque aluden al mismo término -, pareciera que hablan de distintos fenómenos en distintos lenguajes. A nivel geográfico, este número cuenta con contribuciones que observan al populismo desde/ en el 'Norte Global', así como también desde/en el 'Sur Global'. A nivel teórico-disciplinar, este número cuenta con contribuciones que se enmarcan en la sociología de las emociones, la sociología política, la antropología, en los estudios de fronteras de la geografía crítica, en los estudios sobre epistemologías sociales, entre otros.

En lo que sigue, trazaremos tres distinciones con el objetivo de poner en diálogo las contribuciones y descubrir lo que consideramos como coordenadas elementales para una discusión acerca del populismo a partir presentes en este dossier. En un primer momento, mediante la distinción entre acercamientos que buscan atrapar una lógica del populismo y aquellos que buscan explicarlos en su dimensión histórico-concreta, pondremos en diálogo a nuestras contribuciones al tiempo que buscaremos resaltar 
puntos de debate importantes, como el del lugar de los afectos en la política populista. En un segundo momento, nos guiará la distinción entre populismo como fenómeno anti-institucional y populismo como momento instituyente para enmarcar nuestras contribuciones, y resaltar ciertos puntos de encuentro y desencuentro entre las distintas contribuciones. Por último, trataremos acerca de la globalidad del populismo como fenómeno y como categoría, en contraste con su regionalidad en tanto experiencia política. Al final de esta introducción, esperamos poner en evidencia las coordenadas que pueden guiar debates sobre populismo, así como la interrelación entre las distinciones realizadas. De igual manera, se evidenciará y enmarcará la discusión del populismo como tema global con matices particulares y regionales.

\section{I}

Si bien muchas de las ideas que Laclau presenta en La Razón Populista pueden ser tomadas con suspicacia, aceptadas críticamente o rechazadas fervientemente, no cabe duda de que plantea una distinción en las formas de estudiarlo que no es difícil aceptar. O se construye -dice Laclau (2005: 3-10)-, una categoría de populismo a partir de una detallada investigación empírica de sus concretizaciones en busca de elementos que se repiten a nivel causal-contextual o sustantivo-propio, o se busca comprenderlo a nivel abstracto en tanto lógica de articulación política en busca de su propia racionalidad. Se podría decir que, mientras que el primer enfoque busca identificar históricamente contenidos propios del populismo, el segundo apunta a que su identidad reside en la forma en que estos contenidos se organizan formalmente. El artículo de Filipe Carreira da Silva y Mónica Brito Vieira, 'El populismo como una lógica de acción política', contiene una clara exposición de esta distinción, y se sitúa en el lado laclauniano, a saber, en considerar al populismo en su forma abstracta en tanto lógica. Hasta ahí llegan, sin embargo, los acuerdos con Laclau. 
En primer lugar, para Carreira da Silva y Brito Vieira, la lógica del populismo no es una lógica de articulación política y social, como sí lo es para Laclau, sino una lógica de acción política. Esto quiere decir que los autores buscarán una explicación lógico-abstracta que dé cuenta de las motivaciones y posibles desarrollos de la acción política populista. Recorriendo la literatura sobre la lógica del populismo, los autores señalan las limitaciones de los esfuerzos por encapsular las características del populismo al enfoque schmittiano de amistad-enemistad, para ponerlo en una lectura filosófica del resentimiento como fuerza de acción política. Lo interesante es que los autores, a pesar de ligar el populismo con afectos y emociones, buscan comprender la racionalidad y lógica práctico-moral. En la base de esta lógica está la promesa igualitarista de la misma democracia: el resentimiento surge como expresión moral ante la percepción de la ruptura de promesas normativas; opera mediante la asignación de culpables, víctimas y beneficiarios en el marco de una comunidad moral común; y apunta hacia la restauración de las promesas normativas a partir de la restructuración del orden social e institucional. El resentimiento sirve como motivación político-moral para la movilización populista y, en su intrínseca ambivalencia entre la envidia y la indignación, se marca la pauta de las posibles formas en que se desarrolla la acción política populista y su conflictiva relación con la democracia y las instituciones existentes.

Se ha repetido, más allá de los posicionamientos políticointelectuales, que el populismo dice del lugar ineludible de los afectos en la política. Si bien la reflexión sobre los afectos es constitutiva de la filosofía política (Vilas, 2013), el populismo parece constituir la experiencia privilegiada por lo cual los afectos se ubican en el centro, no sólo del discurso político, sino del vínculo establecido entre los gobernantes y los gobernados. El debate en torno a la lógica del populismo, y el lugar de los afectos en esta lógica, se recrea desde acercamientos y separaciones a varios autores. Desde Machiavelo hasta Mouffe, pasando por Weber, 
Schmitt, Laclau o Villacañas, las discusiones sobre cuál es precisamente la articulación del sentido que subyace al populismo representa quizá el lugar donde radican las mayores elaboraciones teóricas. La contribución del artículo de Carreira da Silva y de Brito Vieira es que dilucida este punto al tiempo que abre diálogos con la sociología de las emociones, pero también con la filosofía práctica de raigambre Aristotélica mediante el análisis de la racionalidad práctico-moral, o lógica práctica, de la acción política populista.

William Brickman-Clark, en 'Populismo: entre la razón, la pasión y la lógica de Port-Royal', toma como punto de discusión fundamental el lugar de los afectos en la política populista, pero busca, de igual manera, aunar el populismo al problema de una lógica subyacente. Para BrickmanClark, sin embargo, la lógica del populismo no debe entenderse a nivel discursivo-articulatorio (Laclau) ni de acción política (Carreira da Silva y Brito Vieira): lo característico del populismo es que asienta en una lógica epistemológica distintiva que Brickman-Clark identifica con la Lógica de Port-Royal en oposición a la Lógica Ilustrada. La diferencia entre ambas reside en sus garantías de certeza, lo que definirá la forma en que se articulan 'verdades' populistas y 'verdades' propias de las democracias liberales ilustradas. En el caso de lógica del populismo y de Port-Royal, el garante de certeza es la repetición de ideas preconcebidas, la apelación emocional y a la inmediatez, en oposición a la de la razón ilustrada que asuma una garantía objetiva alejada de las emociones y mediada por instituciones que están ahí para eliminar pre-nociones.

Nicholas De Genova, en su artículo 'Re-delimitando las fronteras del "Pueblo": Apuntes para teorizar el populismo', apunta a descubrir la lógica del populismo en el ámbito de la producción identitaria del Pueblo. Para el autor, la lógica de la producción del Pueblo es equivalente a la lógica de la producción espacial material y simbólica de la Nación. El 'Nosotros, el Pueblo' del populismo es, a decir de Genova, equivalente a un 'Nosotros, el Pueblo de(ntro) esta Nación' Asentado en geografías 
críticas, De Genova considera que un elemento central en la lógica del populismo en la producción del pueblo es la lógica de las fronteras en la producción simbólica, política y material de la nación. No obstante, tal frontera se ve rechazada y superada a través de las prácticas que los sujetos migrantes realizan precisamente cuando se apropian de los instrumentos y mecanismos globales para enfrentar el reducto nacionalista que niega sus derechos universales. Populismo y etno-nacionalismo van de la mano, dice De Genova, y su contrapoder es aquel poder instituyente de la movilidad humana, cuya autonomía busca ser clausurada mediante la re-delimitación de fronteras y pueblos.

El artículo de Rafael Sánchez, 'Los ojos de Chávez: Post-Verdad y Populismo en Venezuela', trata un tema similar al artículo de BrickmanClark, pero desde un enfoque diametralmente distinto. Es distinto, primordialmente, porque no apunta a descubrir una 'lógica' del populismo, sino que, a partir de un estudio empírico detallado de una concretización histórica específica, busca comprender las relaciones ambiguas que el populismo, en general, mantiene con la 'verdad', y con las instituciones y procedimientos democrático-liberales. El autor plantea que la diferencia con los 'antiguos' populismos está en una relación entre líder y 'pueblo' no necesaria ni totalizante, sino contingente, dinámica y momentánea que se asimila a la 'post-verdad' a nivel discursivo, a la ambigüedad tribalizada del pueblo y a la liquidez institucional. Queda para la discusión lo propuesto por Sánchez en relación con estas características de los nuevos populismos que se traducen en 'dominación(es) sin hegemonía' que, como se verá a continuación, encuentra contrapuntos en este mismo número. Es importante resaltar que el trabajo de Sánchez resalta porque analiza el populismo histórica y antropológicamente, al tiempo que ofrece a los interesados en los populismos una construcción a partir de otros referentes teórico-conceptuales, tales como Lacoue-Labarthe, Nancy o Derrida, y propone una serie de conceptos que contribuirán al análisis de otras experiencias globales. 
En la entrevista con Valeria Coronel se pone de relieve otra forma de acercarse al populismo en sus concretizaciones históricas específicas al plantear la idea de 'ciclos de conflictividad'. Los análisis de conflictividad social son análisis de formación histórico-concreta de hegemonía: problematiza el populismo desde las maneras en que el antagonismo político se decanta en las relaciones entre diversos actores a través de negociaciones, pactos y concesiones que hacen posible la conformación del pueblo. Así, el pueblo, más que ser el resultado de la interpelación discursiva de un líder carismático que unifica a la anti-oligarquía o las 'masas disponibles', constituye una formación histórica que integra un acumulado de luchas de diversas tradiciones políticas. La acción política populista, así como su articulación política no puede así explicarse mediante lógicas abstractas. Precisamente, los mecanismos institucionales, culturales, políticos, mediáticos, que permitieron que varias tradiciones políticas se consolidaran como bloque contra-hegemónico son precisamente el contenido del populismo. Entonces, un análisis histórico-crítico del populismo se vuelca hacia los actores y la manera cómo hicieron confluir, en causas comunes, su acumulado político y los medios disponibles para enfrentar al bloque hegemónico.

La producción histórica de tales articulaciones en Ecuador y otros escenarios de América Latina son replanteadas como formación de bloques nacional-populares. Para Valeria Coronel, la aproximación al populismo tiene que ver con la formación de tales bloques que dan cuenta de una manera particular de procesar las crisis y la conflictividad política en distintos periodos. Por lo tanto, históricamente, el análisis del populismo no puede reducirse a identificar los dos extremos del principio schmittiano amigo-enemigo, sino en desentrañar las mediaciones a través de las cuales los actores se constituyen, estratégicamente, como bloque popular. De aquí se sigue que un análisis gramsciano del populismo implica relativizar la figura del líder carismático. Tal como plantea Valeria Coronel, la figura de Velasco Ibarra no expresa las dinámicas del conflicto que se dieron 
en las décadas de 1930 y 1940, ni mucho menos puede dar cuenta de la diversidad de fuerzas de izquierda que dieron forma a la política nacionalpopular. Identificar a Velasco Ibarra desde la semejanza y diferencia que su liderazgo tiene con respecto al de Perón no es el único caso. Dada la relevancia que el análisis del caso de Perón, Vargas y Cárdenas han tenido en el análisis del populismo latinoamericano, éstos han funcionado como formas arquetípicas desde las cuales establecer perspectivas comparativas sobre el populismo latinoamericano. No obstante, el estudio personalista del populismo conlleva a la invisibilización del análisis de la conflictividad.

En este sentido, los trabajos de Rodrigo Iturriza, 'Hacia una economía-política interseccional del populismo: aportes críticos en torno a su forma articulatoria e instituyente' y de Carlos Haynes, 'El momento populista de derechas en Europa. Apuntes sobre el caso español' desarrollan la línea que considera apropiado un análisis del populismo desde la conflictividad establecida. Tanto Haynes como Iturriza plantean el análisis de tal conflictividad dando relevancia a actores políticos que enfrentan el operar del estado argentino y español en coyunturas específicas. Tomar casos particulares no les impide, sino que permite, llevar la discusión a niveles teóricos más abstractos. Así, Iturriza discute con Laclau planteando líneas para el análisis de la cuestión de género en el populismo, mientras Haynes plantea la manera en que los partidos neo-fascistas en Europa integran elementos del populismo en tanto populismo de derecha. Aquí discurre entonces una diferencia entre éstos dos autores. Si bien Haynes sigue a Chantal Mouffe (2009) en su distinción entre populismos de izquierda y de derecha, Iturriza sigue la reformulación del populismo desde sus semejanzas con el republicanismo plebeyo en puntos esbozados por Cadahia y Coronel (2018). Si el texto de Haynes permite comprender cómo las articulaciones políticas entre distintos actores (partidos y movimientos) están históricamente ligadas a una posición ideológica, Iturriza pone un énfasis en la necesidad de ligar la perspectiva de la interseccionalidad (Viveros, 2016) en el análisis de tales articulaciones y propone una noción 
de 'pueblo intersecado' que permite comprender la multiplicidad del pueblo populista en relación con distintas estructuras de dominación.

Una discusión en la que muchas veces no se pone énfasis en debates acerca del populismo y en la que las contribuciones aquí presentadas se posicionan implícita o explícitamente es la intrincada relación del populismo con las instituciones y la forma institucional del populismo. Pareciera que, de las definiciones del populismo, generalmente aceptadas por su ambigüedad, que incluyen una relación directa e inmediata entre el pueblo y el líder, de identificación entre el gobierno y la gente (Abts and Rummen, 2016; Mudde, 2004; Müller, 2016; Urbinati, 2014), se desprende como verdad analítica la destrucción de las mediaciones y una actitud anti-institucional inherente al populismo. Esto explicaría en parte la complicada relación del populismo con los medios de comunicación, así como también con las instituciones. Así, mientras que pareciera que el populismo es un fenómeno anti-institucional por definición, las contribuciones en este volumen toman posiciones o bien más matizadas o bien más positivas en relación a este punto.

Carreira da Silva y Brito Vieira buscan en la lógica del populismo los elementos explicativos de la relación entre populismo e instituciones. Al emerger de los sentimientos morales frente a la traición a principios normativos de la democracia, el populismo tendría un carácter restaurador de democratización de las instituciones existentes, así como también un carácter transformador de instituciones para hacer efectivas las promesas democráticas de autogobierno, soberanía e igualdad. Sin embargo, en su dimensión práctico-moral, el sentimiento moral de resentimiento que está a la base del populismo oscila entre la pura indignación y la envidia radical. Cuando el resentimiento opera según la lógica de la envidia, mas no de la indignación, los impulsos democrático-restauradores del populismo 
se ofuscarían y dominaría un quasi-paranóico, mal direccionado y ciego espíritu de de- y re-institucionalización supuestamente igualitarista. Es interesante que Carreira da Silva y Brito Vieira consideran la relación entre populismo e instituciones a través del prisma de la democracia y sus promesas normativas: la lógica institucional no gira en torno a la inmediatez o mediatez, sino a su desempeño democrático en el sentido más amplio del término.

El ya referido texto de Nicholas de Genova, por su parte, pone en evidencia la relación no del populismo con la Democracia, sino con la Nación, sus promesas identitarias y sus fronteras. De este modo, el argumento implícito es que la forma y el contenido institucional del populismo es la Nación: los proyectos populistas re-instituyen y refuerzan procedimientos e instituciones que apuntan a construir sentidos de pertenencia e identidad nacionalistas y a re-delimitar las fronteras materiales, legales y simbólicas del Pueblo. Las promesas de inclusión y pertenencia, pero también los vicios excluyentes y racistas, están en la base de las formas institucionales del populismo. En relación con la democracia y sus promesas, el carácter nacionalista del populismo - dice De Genova - restringe, en lugar de ampliar, nociones de ciudadanía, derechos, solidaridad y soberanía popular. Esto se evidencia en instituciones (populistas, a los ojos de De Genova) que establecen o refuerzan fronteras materiales o simbólicas entre sujetos de carácter excluyente entre los miembros de la comunidad nacional, y los migrantes o extranjeros.

Las proposiciones abstractas de Carreira da Silva y Brito Vieira acerca del populismo y su relación democratizante con las instituciones resuenan con la postura que se expresa en la entrevista con Valeria Coronel. Sin embargo, para la historiadora, los impulsos institucionales del populismo no se explican a partir de una lógica ahistórica del populismo: hay que entenderlos como el resultado de luchas políticas concretas en que actores sociales buscan hacer hegemónicas visiones políticas e ideológicas específicas. De las pugnas ideológicas y luchas sociales, los populismos derivan su forma y contenido institucional. Los impulsos institucionales 
democratizantes del populismo latinoamericano -- y, en específico, del populismo de izquierda en Ecuador -- se da por la centralidad desarrollada mediante ciclos de conflictividad históricos de disputa por la ciudadanía en los proyectos populistas que se identifica con una visión 'plebeya' o subalterna de las ideologías democráticas liberales y republicanas. Los impulsos institucionales conservadores y excluyentes de los populismos de derecha en España y Europa, siguiendo a Haynes, se explican por la formación histórica de las pugnas ideológicas entre los actores políticos que los conforman.

En su artículo, Iturriza se ocupa de un esclarecimiento conceptual más que de desarrollo categorial. Se da por sentado la asociación de populismo con formas de democracia radical, pero se pregunta cómo hacer evidente su conexión en la dimensión institucional y evaluar sus desempeños. Iturriza sugiere que es posible analizar formas de construcción instituyente-diferencial que siguen al momento equivalencial-intersecado de la construcción del 'pueblo', si se analizan las instituciones populistas a la luz de la forma en que contrarrestan formas de dominación intersecadas al tiempo, así como los usos y apropiaciones de las nuevas instituciones por parte del 'pueblo'. Iturriza proporciona herramientas conceptuales para observar lo que es implícito en Coronel y Haynes: cada populismo desarrolla sus modos institucionales históricamente mediante luchas sociales específicas. En el registro de Iturriza: la forma y contenido institucional del populismo es diferencial y diferenciado porque refleja la construcción interseccional en pugna del pueblo que es múltiple y complejo.

Siguiendo a Villacañas (2015), Brinkman-Clark asume una fuerza anti-institucional en el populismo debido a que este se sustenta en una lógica de la inmediatez. No obstante, más allá de reiterar la históricamente controvertida idea en torno al populismo como una forma destructora de la institucionalidad, se trata de problematizar cómo la anti-institucionalidad del populismo cuestiona 'el fanatismo de la razón' que reduce al pueblo (aquí entendido como el pueblo que surge desde la articulación populista) a una 'minoría de edad'. Así, el populismo propone otro tipo de razón que 
responde al mundo que vive el demos, que propone otra estructuración de las instituciones basadas en la inmediatez y que trata de un discurso coherente que apela a una racionalidad que se separa y diferencia de la liberal. El autor aclara que la diferencia radica en que, siguiendo la lógica de la razón ilustrada, las instituciones se conciben como las garantes de validez del mundo en el que vivimos, mientras que, siguiendo la lógica del populismo - afín a la lógica de Port-Royal -, el garante de verdad está en el solipsismo del pueblo que da forma a las instituciones.

Según se deja entrever, la forma institucional del populismo, de acuerdo al Brinkman-Clark, en lugar de afirmar la mediación institucional en la producción de lo real - tal como lo haría la lógica de la razón ilustrada -, pretende eliminar la distancia (mediación) entre el mundo que prescriben y describen las instituciones liberales y el mundo tal como es vivido y experimentado. Así pues, el impulso anti-institucional del populismo estaría dado por acercar y moldear a las instituciones de acuerdo a la 'verdad' de la experiencia vivida por el pueblo, más no de restaurar y mantener la facticidad y validez institucional existente. A su vez, Sánchez pareciera, a primera vista, estar en el campo contrario que asigna un carácter destructor, anti-institucional al populismo. Definitivamente, Sánchez no otorga contenidos o formas institucionales propias al populismo. Sin embargo, su originalidad reposa en señalar cómo el populismo apunta a instrumentalizar y (des)hacer instituciones con el objetivo de construir constantemente a un pueblo, cuya representación se le escapa con cada intento de nombrarlo debido a la relación dinámica y escurridiza entre 'pueblo’ y líder, entre el pueblo representado y el pueblo existente en concreto.

\section{III}

Con la emergencia de Trump, el triunfo del Brexit, el surgimiento de grupos nacionalistas-populistas en Europa, la consolidación en el poder de Netanyahu en Israel y de Erdogan en Turquía, dicen algunos que el 
populismo se muestra en su globalidad como fenómeno político (de La Torre 2018, Müller 2016). Los intentos teóricos que buscan descifrar una lógica abstracta del populismo desanclada de sus iteraciones históricas y concretas son la contracara de su ubicuidad contemporánea. Si bien estos intentos teóricos arrojan elementos fundamentales para guiar la observación de fenómenos populistas concretos, existen tensiones y desafíos en la elaboración de premisas teóricas.

Una de ellas está en la forma en que se concibe la dimensión nacional del populismo, al igual que su compleja relación con la democracia. Sin duda, una parte fundamental del populismo es la apelación al pueblo y esto remite a un concepto de 'nación'. En otras palabras, no cabe duda de que la 'nación' es parte fundamental de la lógica del populismo. Sin embargo, la categoría de nación tiene distintas trayectorias históricas y políticas, lo que remite a distintas experiencias regionales del fenómeno populista que cortocircuitan cualquier proposición ahistórica de la lógica nacionalista del populismo.

El problema de 'lo nacional' se presenta desde la crítica al nacionalismo como una forma de producción de la comunidad nacional. Esta configuración moderna encuentra en las políticas etnonacionalistas en algunos países europeos, a la vez que en los Estados Unidos de Donald Trump, una expresión que reactiva los fundamentos excluyentes de los proyectos nacionalistas en estos países. En países latinoamericanos, por el contrario, la trayectoria política de la categoría de nación está ligada más a sentimientos e ideas antiimperialistas que a un sentido de pertenencia étnica, más cerca a la expresión de lo nacional-popular que al etnonacionalismo.

La pregunta que se abre es acerca del alcance de generalizaciones teóricas acerca del populismo como lógica de acción política, de articulación discursiva, de formación institucional. Donde éstas terminan, empieza el análisis histórico-concreto de sus 'ciclos de conflictividad', de las 'trayectorias históricas de las categorías políticas', de los discursos de los líderes. El punto de equilibrio, consideramos, sería mostrar las 
coordenadas regionales de los populismos: resaltar las formas concretas e históricas en que operan las lógicas del populismo, llevándolas al nivel de lógicas situacionales más que lógicas abstractas. Agradecemos a todo el equipo de Theorein por el trabajo en la edición de este número; a los autores, con quienes hemos mantenido intensa, pero gratificante, correspondencia, por compartir con nuestra revista sus interesantes ideas; y a South Atlantic Quarterly por cedernos los derechos de traducción del artículo de Nicholas De Genova. La llegada de Joseph Salazar al equipo de Theorein y de Jorge Daniel Vásquez como nuevo co-jefe editorial de la revista es más que bienvenida. Estamos seguros de que la revista encontrará nuevos rumbos, se refrescará y renovará. 


\section{Referencias}

Abts, K. \& Rummen, S. (2007) Populism versus Democracy. Political Studies, 55: 402-24.

Arditi, B. (2004) Populism as a Specter of Democracy. A response to Canovan. Political Studies 52, no 1: 135-143.

Cadahia, L. (2016) "Espectrologías del populismo en Ecuador: materiales para una lectura renovada de la Revolución Ciudadana" en Le Quang, M. (ed). La Revolución Ciudadana en escala de grises. Avances, continuidades, desafios. IAEN: Quito

Cadahia, L. \& Coronel, V. (2018) Populismo republicano: más allá de “Estado versus pueblo”. Nueva Sociedad, 273: 72-82.

De La Torre, C. (2018) Populisms. A Quick Immersion. Middletown: Tibidabo Publishing

Ionescu, G. \& Gellner, E. (1969) Populism. Its meaning and national characteristics. Weindenfeld and Nicholson: London

Knight, A. (2005 [1992]) "Populismo y neopopulismo en América Latina, especialmente México” en Revolución, Democracia y Populismo en América Latina. Santiago de Chile: Centro de Estudios Bicentenario.

Laclau, E. (2005) La Razón Populista. Buenos Aires: Fondo de Cultura Económica

Mudde, C. (2004) The Populist Zeitgeist. Government and Opposition 50: 189-217.

Müller, J. W. (2016) What is populism? Philadelphia: University of Pennsylvania Press

Mouffe, C. (2009) El fin de la política y el desafío del populismo de derecha. En: Panizza, F. El populismo como espejo de la democracia (págs. 71-96). Buenos Aires: FCE. 
Panizza, F. (2009) "Introducción. El populismo como espejo de la democracia." En El populismo como Espejo de la Democracia, editado por Francisco Panizza, 9-49. México D.F.: Fondo de Cultura Económica

Urbinati, N. (2014) Democracy Disfigured. Cambridge: Harvard University Press.

Vilas, C. M. (2013) El poder y la política. El contrapunto entre razón y pasiones. Buenos Aires

Villacañas, J. L. (2015) Populismo. Madrid: La Huerta Grande

Viveros Vigoya, M. (2016) "La interseccionalidad: una aproximación situada a la dominación”. Debate Feminista, 52, 1-17. 